\title{
Time and reglamentary analysis during high level wheelchair basketball competition: training conclusions
}

\section{Análisis temporal y reglamentario en el baloncesto en silla de ruedas de alto nivel: conclusiones para el entrenamiento}

\author{
Javier Pérez Tejero*, Javier Pinilla Arbex, Jesús Aceituno Duque, and Javier Sampedro Molinevo
}

Cátedra "Fundación Sanitas" de Estudios sobre Deporte Inclusivo, Facultad de Ciencias de la Actividad Física y el Deporte (INEF), Universidad Politécnica de Madrid (UPM) (Spain).

Abstract: One of the key factors while determining physical effort in a collective sport is the analysis of the duration of game actions, reglamentary pauses and their origin. Therefore, the aim of this study was to analyze the incidence of the game and pause phases in wheelchair basketball, as well as the duration and frequency of events triggering those pauses. A systematic observation was carried using an ad hoc observational instrument on a total of 24 high level WB matches, where 17 teams participated. $56959 \mathrm{~s}$ were analyzed, with an average of $4773 \pm 567 \mathrm{~s}$ per game, distributed in $80.5 \pm 14.2$ game action phases and $77 \pm 14.7$ pause phases, being their duration $29 \pm 25 \mathrm{~s}$ and $30 \pm 39$ s, respectively. $47,1 \%$ of game situations took less than $20 \mathrm{~s}$ and just the $11,8 \%$ took more than $60 \mathrm{~s}$. The $50,1 \%$ of the pause phases were shorter than $20 \mathrm{~s}$ and just the $9,9 \%$ was superior to $60 \mathrm{~s}$. Personal faults and out of bounds were the regulation incidences which developed more pause phases $(85,4 \%$ of the total). These data provide crucial information to the coaches to frame physical training in order to replicate sport specific exigency of elite wheelchair basketball.

Key words: wheelchair basketball; Paralympic Games; time analysis; sport performance.
Resumen: Uno de los aspectos fundamentales para determinar la exigencia física en un deporte colectivo es el análisis de la duración de las acciones de juego, las pausas reglamentarias y su origen. Por ello, el objetivo del presente estudio fue analizar la incidencia de las fases de juego y de pausa en el baloncesto en silla de ruedas, así como la duración y frecuencia de los eventos que generan dichas pausas. Se realizó una observación sistemática con un instrumento de registro desarrollado ad hoc sobre un total de 24 partidos de BSR de alto nivel, en los que participaron 17 equipos. $56959 \mathrm{~s}$ fueron analizados, registrándose de media por partido de $4773 \pm 567 \mathrm{~s}$, distribuidos en $80,5 \pm 14,2$ fases de participación y $77 \pm 14,7$ fases de pausa, siendo su duración $29 \pm 25$ s y $30 \pm 39$ s, respectivamente. El $47,1 \%$ de las fases de participación duraron menos de $20 \mathrm{~s}$ y solo el 11,8\% duró más de $60 \mathrm{~s}$. El $50,1 \%$ de las fases de pausa fue menor a $20 \mathrm{~s}$ y solo el $9,9 \%$ fue superior a $60 \mathrm{~s}$. Las faltas personales y las fueras de banda fueron las incidencias reglamentarias que más pausas desencadenaron $(85,4 \%$ del total). Estos datos proporcionan información crucial a los entrenadores para encuadrar el entrenamiento físico con el fin de replicar la exigencia específica del deporte del baloncesto en silla de ruedas de élite.

Palabras clave: baloncesto en silla de ruedas, Juegos Paralímpicos, análisis temporal, rendimiento deportivo.

\section{Introduction}

One of the determining factors to precise physical exigency in a collective sport is the duration of game actions and the subsequent pauses, as well as the causes occasioning these interruptions (Barbero, 2003; Ferreira, Ibáñez y Sampaio, 2009). Lorenzo (2000) considered that one of the key characteristics of basketball regulation is its great complexity, defining this parameter while comparing with other sports. The meticulousness of the regulation, especially regarding temporary administration, makes it necessary to study the relationship between the game action and pause phases with the aim of defining the precise density of physical effort. In wheelchair basketball (WB), the interest in performance has suffered a sharp and necessary increase for the quantitative and qualitative improvement of training systems in the recent years (Gómez, Pérez-Tejero, Molizk, Szyman \& Sam-

Dirección para correspondencia [Correspondence address]: Javier Pérez Tejero.E-mail: j.perez@upm.es paio, 2014; Pérez-Tejero \& Pinilla, 2015; Pérez-Tejero, Rabadán, Pacheco \& Sampedro, 2007; Pérez-Tejero \& Sampedro 1999; Sporner et al., 2009). A first analysis of the rules offers key information on WB nature, this sport is played in 4 periods of 10 minutes each, with a predetermined pause of 2 minutes between quarters and 10 minutes by the half of the match, being $24 \mathrm{~s}$ the possessions duration (IWBF, 2017). Consequently, analyzing the duration of game actions and pause phases taking place in these periods may generate relevant information which will lay the foundation for a specific WB training methodology, especially regarding physical requirements.

Defining the relationship between game actions and pause phases in a collective sport, as well as their origin, equates to the assessment of an external load indicator to which players are subject during the competition (Cárdenas, 1996; Barbero, 2003). This is an objective measure performed by the player and is independent of the internal load (Mujika, 2013): this 
being the volume, frequency, intensity, density and specificity (Schelling and Torres-Ronda, 2013). This indicator is of the outmost importance in this type of sports, since it enables competition time organization to be interpreted and framed, planning and modeling training in order to adapt the contents to the actual competitive demand (Zaragoza, 1996; Ferreira, Ibáñez y Sampaio, 2009), establishing appropriate strategies according to the specific structure of the analyzed sport (Grosgeorge, 1990), as well as prescribing and basing a framework on the regulation of training/learning situations (Riera, 1995; Sampedro, 1999).

In our opinion, for WB characterization, the relationship between game actions and pause phases must be accompanied by the causes originating such interruptions in the game. The application of rules along the match, and studying them, derives in the characterization of two specific, but highly related, structural parameters: time and rules. The rules and their application by the referees during the game will determine, in each case, one type of event or another. It is impossible to determine beforehand which the next pause in a WB game will be, when will it take place, what will its cause be or its duration, due to the "implicit uncertainty" in this type of sports. Nonetheless, it is possible to develop an analysis of these incidents and their duration, with descriptive purposes and with the aim of describing normative patterns of the duration of actions, pauses, as well as the characterization of events (Barbero, 2003; Ferreira, Ibáñez y Sampaio, 2009). Considering the aforementioned contributions, the aim of the present study was to analyze the time features of high level WB competition through action and pause phases analysis, and to determine the reglamentary events triggering those pauses along game development.

\section{Methodology}

\section{Sample}

A total of 24 high level WB competition games were studied, 12 of which belong to Spanish "Honour Division" League (top league in Spain for clubs), 7 to the European Champions Cup League (top league in Europe for clubs) and 5 to the Spanish "King's Cup" (top play off tournament in Spain for clubs). A total amount of 17 different high level teams were studied in the analyzed matches.

\section{Observational procedure}

Systematic observation and registration of game action and pause phases during WB competition was established along 5 pilot games, in order to determine the referred objectives. That is why the analysis is based on the defi- nition of a specific observational methodology as a procedure for the perception and evaluation of these phases. This has been done through the employment of an ad hoc notational analysis instrument which allows an objective, systematic and specific register of the (action and pause) phases (Anguera, 1988), analyzing the specific work-rate in this sport (Hughes \& Franks, 2004). Therefore, the specific objective of the observation in this study was the registration of the time lapse of game action and pause phases, as well as the definition of the reglamentary event causing those interruptions along a sample of matches in the indicated WB competitions.

The observational sampling used was occurring order, which registered sequentially the fact taking place and its duration every time it happened (Anguera et al., 2011). These facts were classified as categories. The tool designed registered sequences in chronological order, from the moment the sequence started to the moment it ended, followed by another sequence. The elaboration of a category system supposed the creation of a measuring instrument of observational investigation, and it resulted in a continuous process of depuration and optimization until a valid category system was obtained for the purpose of the investigation. At the end of the process, the criterion from IWBF rules prevailed to define the observation tool, with a final selection of the detailed categories in Table 1, being those codified according to the observation sheet designed to this purpose. For research purposes, it was decided to define an action phase as the time lasting from the moment that the game clock starts running to the moment it is stopped (Sampedro, 1999), in accordance with the criteria established by the referees: sound of the whistle and vertical raise of the referee's arm, signaling that the game clock should be stopped (status of the ball "live", article 10; IWBF, 2017); on the other hand, pause phases (the match timer is stopped) are those in which there is a stop in the game time because a reglamentary event had occur in between successive game intervals (periods) or action phases (Sampedro, 1999). This temporal aspects of the game are defined in the game rules (status of the ball "dead", article 10; IWBF, 2017).

Table 1. Category system developed for time analysis in wheelchair basketball, type of reglamentary event and its definition.

\begin{tabular}{ccc}
\hline Game situation & Definition & Abbreviation \\
\hline Action phase & Game action & $\mathrm{G}$ \\
\hline Pause phase $^{*}$ & Personal foul & $\mathrm{PF}$ \\
Direct & Out of bound & $\mathrm{OB}$ \\
" & 24 s violation & $24 \mathrm{~V}$ \\
" & 8 s violation & $8 \mathrm{~V}$ \\
" & 3 s violation & $3 \mathrm{~V}$ \\
\hline
\end{tabular}




\begin{tabular}{ccc}
\hline Game situation & Definition & Abbreviation \\
\hline " & Ball returned to the backcourt & $\mathrm{BR}$ \\
" & Alternating possession & $\mathrm{AP}$ \\
" & Travelling & $\mathrm{T}$ \\
& Violation because falling of \\
player in possession of the ball & $\mathrm{F}$ \\
& Game clock stopped after \\
scored basket & $\mathrm{B}$ \\
Indirect & Others & $\mathrm{O}$ \\
" & Time out & TO \\
" & Substitution & $\mathrm{S}$ \\
& Free throw & FT
\end{tabular}

${ }^{*}$ For pause phases, distinguishing between those direct pause events (D, directly indicated by referee) and indirect pause events (I, necessary following a direct pause).

According to the reglamentary events (cause of a given pause phase), a previous pilot study determined the definition of a "hierarchical status" of pause applications. The reglamentary events related pause phases were divided in two groups: a) "direct pause events", those called by referees during the development of the game including: foul (PF, including game, technical, unsportsmanlike and disqualifying fouls), out of bound $(\mathrm{OB}), 24 \mathrm{~s}$ violation $(24 \mathrm{~V}), 8 \mathrm{~s}$ violation $(8 \mathrm{~V}), 3 \mathrm{~s}$ violation $(3 \mathrm{~V})$, ball returned to the backcourt $(\mathrm{BR})$, alternative process (AP), travelling ( $\mathrm{T})$, violation because falling of player in possession of the ball $(\mathrm{F})$, game clock stopped after basket (B, last two minutes of $4^{\text {th }}$ period), others (ball stacked in the basket-blackboard, fall of a players along game with possible danger because game situation, other unpredictable events, etc.) and b) "indirect pause events" are those generated by one of the previous direct events and they are posteriorly applied, but included in the duration of the same pause: Time out (TO, can include substitution), substitution (S) and free throw (FT, Following a PF, can be 1,2 or 3 ).

In order to record matches, a Casio "Exilym" digital video camera mounted on a Manfrotto ${ }^{\oplus}$ tripod were used. Along the duration of each match, the camera was placed in a central position, elevated in one of the lateral tribunes of the stadium. In this way, almost the whole half of the court in which the action of the game was being developed was included in the recorded frame. The person responsible of filming attempted to follow the game globally, always orienting the camera in the direction of the ball. Only the periods in which the game was in process were recorded, stopping the filming process during the pauses between quarters $(2 \mathrm{mi}$ nutes between periods and 10 minutes). After filming them, recordings were analyzed by the observers, who filled in the designed observation sheets for each of the 24 studied games. Each game was classified and codified in order to undergo observation by the observers, who codified all the game si- tuations for a given match, as well as their duration, in s, in the indicated observation sheet. The tool for the observation register was designed and created in "Excel" format to ease transferring the data to the statistical software SPSS 19.0 (SPSS Inc., Chicago, IL, USA). Both, action and pause phases were computed, calculating their duration, total average duration and the standard deviation. Finally, reglamentary events provoking pauses were analyzed and temporarily characterized as determining factors in the detention of the game clock. The sensibility of the employed system was $\pm 1 \mathrm{~s}$.

\section{Reliability of the observation}

Two trained observers (pilot study consisting of three matches) took part in the observation and codification of the analyzed games. Regarding the appropriateness of the developed tool and its application, the consistency among observers was assessed in order to define each sequence regarding every described category, using the percentage of agreement between observers, which was the $98 \%$ of occasions. Those rare data in which there existed a discrepancy or doubt among the observers were assessed by an expert who enlightened the observers with his criterion. Moreover, to assess the reliability of the evaluation of the time lapse of each sequence, a correlation Pearson coefficient was used, resulting in $\mathrm{r}=0,99$ $(\mathrm{p}<0,05)$. In both cases, three full games were employed for the analysis, being the three observers tested. The procedures followed to evaluate the reliability are those indicated by Del Rincón et al. (1995).

\section{Results}

\section{Action and pause phases}

The total duration of the 24 studied matches was of 31 hours, 28 minutes and $33 \mathrm{~s}$ (56959 s in total) divided in 3878 game situations (action and pause phases). The total amount of duration for action phases was 15 hours, 49 minutes and $19 \mathrm{~s}$ (n= 1933), meanwhile for pauses phases was 15 hours, 39 minutes and $14 \mathrm{~s}(\mathrm{n}=1849)$.

Tabla 2. General data for action and pauses phases for the total of the games analyzed.

\begin{tabular}{ccc}
\hline & Action phases & Pauses phases \\
\hline Total number & 1933 & 1849 \\
Total duration & $15: 49: 19$ & $15: 39: 14$ \\
Average per game & $80,5 \pm 14,2$ & $77,0 \pm 14,7$ \\
Average duration & $29 \pm 25 \mathrm{~s}$ & $30 \pm 39$ \\
Minimum duration & $1 \mathrm{~s}$ & $1 \mathrm{~s}$ \\
Maximum duration & $163 \mathrm{~s}$ & $313 \mathrm{~s}$ \\
\hline
\end{tabular}


Time intervals grouping of the data from both type of phases will show a more coherent profiling, detailing the durations taking place more often in the development of a match. Therefore, data was treated following the grouping criteria to ensure their congruence. On one hand, data was grouped every $20 \mathrm{~s}$ (Figure 1), as the classic study on the duration of game phases in classical basketball studies by Colli \& Faina (1987) did. On the other hand, data were grouped every 5 $\mathrm{s}$, as it was done in the basketball study by Papadopoulos et

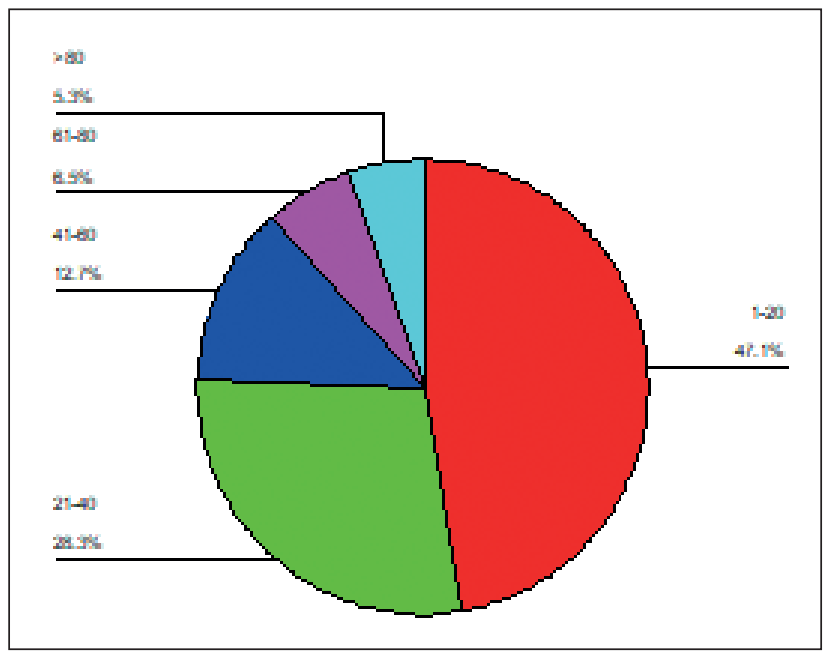

Figure 1. Action (left) and pause (right) phases duration grouped every $20 \mathrm{~s}$ and their distribution percentages.

When data were grouped every five s (Figure 2), it can be observed that for the action phases, the interval ranging from 6 to $10 \mathrm{~s}$ encompassed $14,1 \%$ of data; the period between 11 and $15 \mathrm{~s}$ covered the $13,1 \%$ of data and the one between 16 and $20 \mathrm{~s}$ encompassed the 11,0\%: the three mentioned intervals comprised the $39 \%$ of all the action phases and together with the interval $1-5 \mathrm{~s}$, they reach $47,1 \%$ of the total. From the second grouping interval (6-10 s), the duration progressively decreases to its extinction. Action phases lasting over two minutes and a half took place just the $0,2 \%$ of the al., (2002). 47,1\% of the action phases lasted up to $20 \mathrm{~s}$ and almost a third of them $(28,3 \%)$ lasted between 21 and $40 \mathrm{~s}$; also, $88.2 \%$ of the these phases lasted less than one minute of duration; finally, action phases above $80 \mathrm{~s}$ accounted for $5.3 \%$ of the total. For pauses phases, $50,1 \%$ of the action phases lasted up to $20 \mathrm{~s}$ and 26,2\% lasted between 21 and $40 \mathrm{~s}$; $90.1 \%$ of the pause phases lasted less than one minute, while those above $80 \mathrm{~s}$ accounted for $5.1 \%$ of the total (Figure 1).

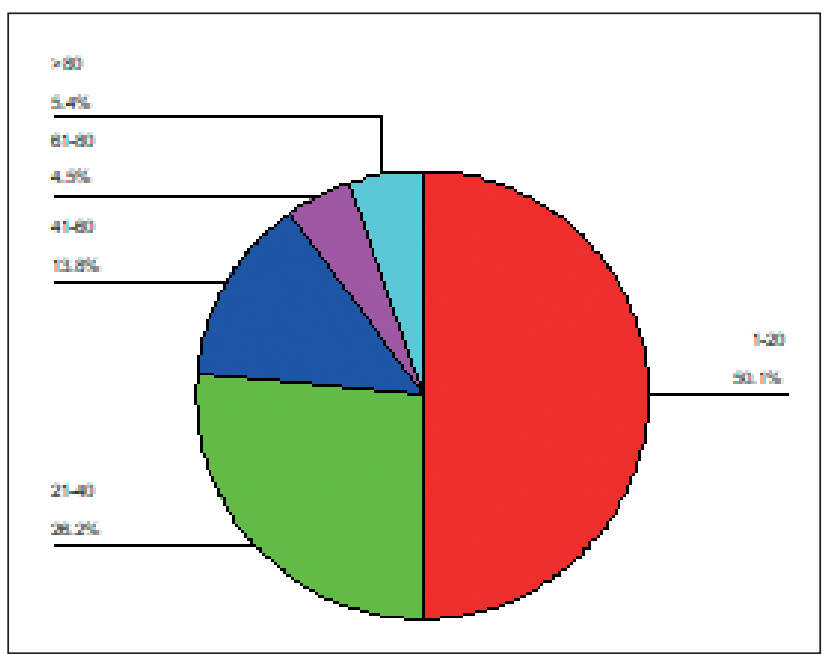

cases. Regarding pause phases, $5 \mathrm{~s}$ interval grouping offers a very similar profile, although some considerations were made. The most frequent interval was the one involving the phases lasting between 16 and 20 s, which accounts for $17.1 \%$ of the total data, followed by the interval comprising 11 to 15 $\mathrm{s}(15.9 \%)$ and in the last place the 6 to $10 \mathrm{~s}$ interval (13.0\%). The three mentioned intervals accounted for $46.0 \%$ of the total pause phases. These three, along with the first interval (1-5 s, $2.1 \%$ ) reached $50.1 \%$ of the total pause phases. 


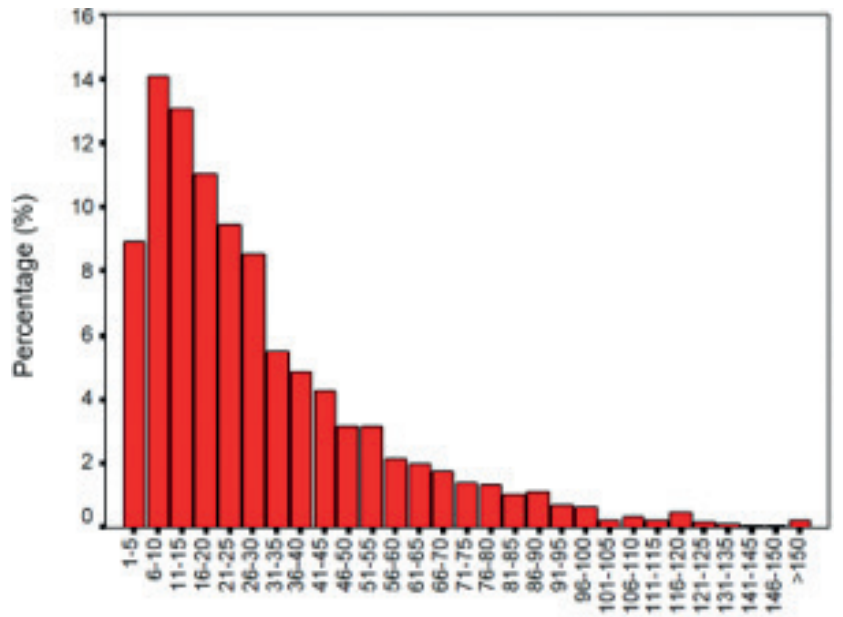

Action phases intervals (every $5 \mathrm{~s}$ )

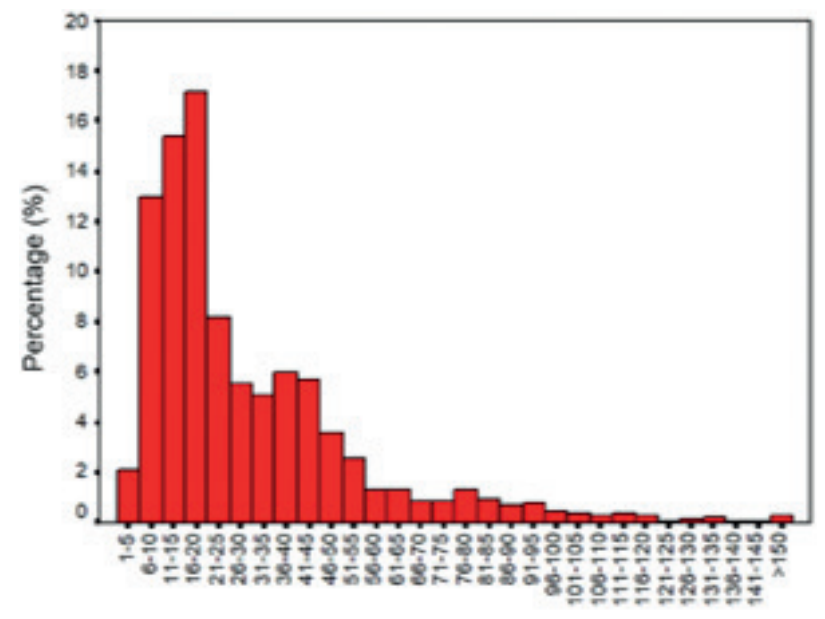

Pause phases intervals (every $5 \mathrm{~s}$ )

Figure 2. Action and pauses situations in $5 \mathrm{~s}$ intervals and contribution to total percentage.

Reglamentary events causing pause phases

In Table 3 an analysis of theses incidences is presented. It should be noted that almost half of the pauses were due to the indication of a PF (48.2\%), while a third of them corresponded to $\mathrm{OB}(33.5 \%)$. Both together account for $81.7 \%$ of these reglamentary incidences.

Table 3. Distribution of reglamentary incidences causing pause phases.

\begin{tabular}{cccc}
\hline Reglamentary event & Total frecuency & Frecuency per game & $\%$ \\
\hline PF & 892 & 37,2 & 48,2 \\
OB & 619 & 25,8 & 33,5 \\
O & 133 & 5,5 & 7,2 \\
$24 \mathrm{~V}$ & 66 & 2,8 & 3,6 \\
3V & 55 & 2,3 & 3,0 \\
AP & 24 & 1,0 & 1,3 \\
B & 14 & 0,6 & 0,8 \\
BR & 13 & 0,5 & 0,7 \\
F & 13 & 0,5 & 0,7 \\
T & 11 & 0,5 & 0,6 \\
$8 V$ & 9 & 0,4 & 0,5 \\
Total & 1849 & 77,0 & 100,0 \\
Lost cases & 96 & 4,0 & 4,9 \\
\hline
\end{tabular}

\section{Discussion}

The aim of this study was to analyze and characterize the game situations (action and pause phases) as well as the reglamentary incidences taking place during WB high level com- petition through notational analysis. The obtained results provide relevant information in order to determine the density of the effort in this sport modality, as well as to guide future interventions while planning physical training of WB players. To the knowledge of the authors, there are few studies which directly analyze the players' external physical effort deriving from competition for this sport modality. One of these investigations was carried out by Sporner et al. (2009) by means of a pilot study in which the WB players performances were analyzed along a veterans' competition in Canada. The authors showed that for an average playing time of $30.29 \pm$ $9.59 \mathrm{~min}$, each player average tour was $2679.52 \mathrm{~m} \pm 1103.66$ $\mathrm{m}$ at an average speed of $1.48 \pm 0.13 \mathrm{~m} / \mathrm{s}$. Considering all these players' movements a total of $239.78 \pm 60.61$ stops and starts took place. Another of the studies regarding this topic was carried out by Bloxham et al. (2001), in which the type of actions developed during the game time were analyzed; the main results were the following: players spent $8.9 \%$ of the time sprinting, $23.5 \%$ sliding, $18.2 \%$ struggling for the ball, $0.6 \%$ sprinting with the ball, $0.3 \%$ shooting and the remaining $48.3 \%$ players were still or at the bench. However, the study of density in this sport has not been referenced so far, despite being one of the aspects studied in literature for the definition of the global requirement profile in team sports as an external load indicator of a sport practice intensity.

One important issue is related to time a given WB player is on court during the game, as it is a decision of the coach, and the importance the time the player is on the bench is crucial to determine global external load. In this regard, PérezTejero, Rabadán, Pacheco and Sampedro (2007), in their study concerning heart rate during WB high level competition, found that the five studied players were on court for most of the competition (more than the $50 \%$ of game time: 21 
minutes and $36 \mathrm{~s}$ per match and player), but overall physical demand for all players was quite different, while the relationship between action and pauses situations was almost equal, creating a competition density close to 1:1. Per player, the time spent in offense $(22,3 \%$ of data collected) was similar to the time spent in defense $(27,3 \%)$ for all players, while the time spent on court was recorded during pauses created by game officials (50.4\%). However, taking into account the time the player spent on the bench, these authors found three "main" categories of general status of every player: player on the bench (33\% of time), pauses phases (33\% of time), and action phases (33\% of time). So, regarding the whole event of competition, $2 / 3$ of the total time players are in some type of pause situation (on court or on the bench). This should be also be taken into consideration when determining external load from real competition and/or tournaments.

According to the results obtained in this study, the intervallic nature of WB seems obvious, being this game aspect the one apparently giving relevance to anaerobic capacity in this sport, as indicated by previous studies (Molik et al., 2013). The definition of the duration of different game situations and pause phases is crucial when defining this external aspect of the profile of exigency in this sport. In the present study, the average duration of the game situations was $29 \pm 25$ $s$ and $30 \pm 39$ for pause phases. These data are in accordance with the previously evaluated data by Pérez-Tejero \& Sampedro, (1999) for WB, who presented the average data of 31.5 and $21.3 \mathrm{~s}$ for game situations and pause phases, respectively. Likewise, the data analyzed in this study are very close to those evaluated by Papadopoulos et al., (2002) in running basketball, who recorded an average length of $31 \mathrm{~s}$ for the participation phases and $35.2 \mathrm{~s}$ for the pause phases.

Regarding frequency of action and pause phases, in our opinion, this is one of the most important indicators provided by this analysis of the competition. There were an average of 80.5 game situations and 77 pause phases per game, while the game situations and pause phases accounted for $50.3 \%$ and $49.7 \%$ of the total data, respectively. The total number of phases was 157.6 phases. These data are very similar to those shown in Papadopoulos et al. (2002) study, in which they displayed an average frequency of 78.4 and 74.3 phases per game, for action and pause phases, respectively; meanwhile the total amount, for the latter study, rose to 152.8. On the other hand, the study by Pérez-Tejero and Sampedro, (1999, on the 2nd National Spanish Division), shows a frequency of 56.8 (game situations), 54.1 (pause) and 113.6 (total). These data grow apart from those evaluated in the two previously cited studies, perhaps because of the difference in the level of competition or the regulatory changes produced between the two competitions (30-second possessions and 20-minute periods on those previous studies).

Considering game situations, regarding Sampedro and
Cañizares (1993), Colli and Faina (1987) and Hernández (1988) studies; we found that this study threw results similar to those given by Hernández (1988), highlighting the fact that the data of the present study are the ones with the highest percentage of data registered under $40 \mathrm{~s}$ (75.4\%) and one minute (90.1\%). Equally, the fact that while grouping game situations the highest percentage for the first group $(0$ to $20 \mathrm{~s}$ ) was recorded in this study, with $47.1 \%$ the data, needs to be highlighted. From our perspective, this is one of the computable consequences derived from the decrease in ball possessions duration due to the last change in the regulations (see Table 3). Pause phases in terms of duration provided a great correspondence with the distribution of the percentage in participation phases. Thus, the total amount of pauses having a duration inferior to $40 \mathrm{~s}$ approximately accounts for the $75 \%$ of the total (76.3\%). It is outstanding the similarity between the illustrations of grouping data every $20 \mathrm{~s}$ in Colli and Faina's (1987) study and the ones of our own study. This resemblance shows the proportionality of participation and pause phases duration distribution. However, the previously referenced studies were all developed previous to the year 2000, which is the reason why ball possessions duration was of $30 \mathrm{~s}$ when they were carried out. The only previous study, in our knowledge, regarding the density of WB game (Pérez-Tejero \& Sampedro, 1999), the duration, for the pause phases between $0-20 \mathrm{~s}$ recorded the $65.8 \%$ and between $20-40$ s $20.5 \%$. Both of which account for more than $85 \%$ of the total regulatory incidences evaluated. This percentage exceeds the registered data in the present study by a $10 \%$, with a total percentage, already indicated, of $76.5 \%$ for those pause phases below $40 \mathrm{~s}$, distributed as follows: $50.1 \%$ for those between the $0-20 s$ and $26.2 \%$ for those registered between $21-40 \mathrm{~s}$.

Concerning reglamentary incidences, the most frequent was PF (with $48.2 \%$ of the total data and an average frequency per game of 37.2 times), the $\mathrm{OB}$ (comprising $33.5 \%$ of the total data and an average frequency per match of 25.8 times) and $\mathrm{O}$ (with $7.2 \%$ of the registered data and an average frequency of 5.5 times). All of them represent $82 \%$ of the total pauses. The remaining incidences do not reach either $5 \%$ of the total amount or more than 3 times per game. In order to analyze those action pauses phases of indirect nature, it was necessary to obviate the previous grouping criterion regarding direct incidents. Therefore, those times in which the indirect incidence appeared isolated were analyzed, although, of course, it was analyzed accompanied by the incidence that triggered the pause. For example, for the FT incidence (including 1, 2 or 3 FT), when it occurred without any further incident, it had a mean frequency of 12.5 times $(n=300)$ per game, with an average duration of $41 \pm 10$ s. Obviously, there was always a PF that triggered the situations in which there was a FT. Another example is TO, with a mean frequency 
per game of $5.7(n=100)$ and an average duration of $87 \pm 22$ s. These were triggered $47 \%$ of times by OB, $39 \%$ by PF and $7 \%$ by $\mathrm{O}$, being other events the cause of $\mathrm{TO}$ the remaining $7 \%$.

\section{Conclusions and training applications}

This study provides key information to the coaches to frame physical training in order to replicate sport specific exigency of elite wheelchair basketball. In this line, we can emphasize the following aspects related to WB physical training specific design based on the study findings:

- Since the mean duration of game situations was $29 \pm 25$ $s$ and $30 \pm 39 s$ for pause phases, the distribution of the loads in order to improve the anaerobic capacity in WB players should follow the same action-pause relationship.
- The highest load that a player could undergo in a game (live ball) is 40 minutes (if there are no extensions). In these 40 minutes, this study indicates that the pattern of action/pause phases is $80 / 77$. It should be noted that the regulation stipulates 3 mandatory breaks between each quarter.

- During game situations, the duration of the effort is no longer than $20 \mathrm{~s}$ in $47.1 \%$ of the cases and only in $11.8 \%$ is greater than $60 \mathrm{~s}$. Therefore, these timings should serve as a reference in order to plan loads durations in WB training.

- The pause phases analyzed in this study provide a reference to the recovery time available to the player(s) during a match. According to the results, $50.1 \%$ of the pauses are shorter than $20 \mathrm{~s}, 26.2 \%$ range from 21 to $40 \mathrm{~s}$ and only $9.9 \%$ of the pauses are longer than $60 \mathrm{~s}$.

\section{References}

1. Anguera, M.T. (1988). Metodología de la observación en las Ciencias Humanas ( $3^{\mathrm{a}} \mathrm{ed}$ ampliada). Madrid: Cátedra.

2. Anguera, M.T. (1990). "Metodología Observacional". En Arnau J., Anguera M.T. \& Gómez J., Metodología de la investigación en Ciencias del Comportamiento. Murcia: Secretariado de Publicaciones de la Universidad de Murcia.

3. Anguera, M.T., Villaseñor, A.B., Hernández-Mendo, A. \& Losada, J.L. (2011). Diseños observacionales: ajuste y aplicación en psicología del deporte. Cuadernos de psicología del deporte, 11(2), 63-76.

4. Barbero, J.C. (2003). Análisis cuantitativo de la dimensión temporal durante la competición en fútbol sala. European Journal of Human Movement, 10, 143-163.

5. Bloxham, L.A., Bell, G.J., Bhambhani Y. \& Steadward R.D. (2001). Time motion analysis and physiological profile of Canadian world cup wheelchair basketball players. Research in Sports Medicine, 10(3), 183-198

6. Cárdenas, D. (1996). Necesidades del jugador de baloncesto en cuanto a preparación física. Características y aplicación de la estructura de bloques a los deportes de equipo. Límites de la concentración del entrenamiento. In "I Jornadas sobre Preparación Física en deportes de equipo", Málaga: Instituto Andaluz del Deporte.

7. Colli, R., \& Faina M. (1985). Pallacanestro: riserca sulla prestazione, Rivista de Cultura Esportiva, 2, nuova serie, 24-29.

8. Ferreira, A.P., Ibáńez, S., \& Sampaio, J. (2009). Las reglas y la casualidad en Baloncesto: una aproximación histórica. Retos: nuevas tendencias en educación física, deporte y recreación, 15, 9-13.

9. Gómez, M.A., Pérez-Tejero, J., Molizk, B., Szyman, J., \& Sampaio, J. (2014). Performance analysis of elite men's and women's wheelchair basketball teams. Journal of Sport Sciences, 32(11), 1066-1075.

10. Grosgeorge, B. (1990). Observation et entreinement en sports collectifs, Paris: Insep Publications.

11. Hernández, J. (1988). Baloncesto, iniciación y entrenamiento". Colección Deporte, Paidotribo. Barcelona.

12. Hughes, M., \& Franks, I. M. (Eds.). (2004). Notational analysis of sport: Systems for better coaching and performance in sport. Psychology Press.

13. IWBF (2017). Official Wheelchair Basketball Rules. International Wheelchair Basketball Federation (IWBF).

14. Lorenzo, A. (2000). Buisqueda de nuevas variables en la detección de talentos en los deportes colectivos. Aplicación al baloncesto. Doctoral dissertation, Universidad Politécnica de Madrid.
15. Medina-Carrillo, J., García-Tormo, J. V., Morante-Rábago, J. C., \& Rodríguez-Marroyo, J. A. (2016). Análisis notacional de las acciones de juego realizadas por jugadoras de voleibol en competición universitaria. SPORT TK-Revista EuroAmericana de Ciencias del Deporte, 5(2), 113122.

16. Molik, B., Laskin, J.J., Kosmol, A., Marszalek, J., Morgulec-adamowicz, N., \& Frick, T. (2013). Relationship between anaerobic performance, field tests, and functional level of elite female wheelchair basketball athletes. Human Movement, 14(4), 366-371.

17. Mujika, I. (2013). The alphabet of sport science research starts with Q. International Journal Sports Physiol Perform, 8(5), 465-466.

18. Papadopoulos P., Schmidt G., Stafilidis S., Baum K. (2002). The characteristics of the playing and break times of a basketball game. Proceedings of the $7^{\text {th }}$ Congress of the European Congress of Sport Sciences, Ed. Koskolou M., Geladas N., Klissouras V., Athens, Greece.

19. Pérez-Tejero J., \& Sampedro J. (1999). Movement evaluation and ratio action/pause of the wheelchair basketball player: training conclusions. Proceedings of the $12^{\text {th }}$ International Symposium for Adapted Physical Activity, INEFC - ISAPA, Barcelona - Lérida.

20. Pérez-Tejero J., Rabadán M., Pacheco J.L., Sampedro J. (2007). Heart rate assessment during wheelchair basketball competition: its relationship with functional classification and specific training design. In Sport for Persons with a disability. Perspectives, Colin Higgs \& Yves Vanladewijck (Eds.), ICSSPE - IPC, volume 7, 151-174.

21. Pérez-Tejero, J., Pinilla, J. (2015). Rendimiento del jugador de baloncesto en silla de ruedas según la estadística de juego. Cuadernos de Psicologia del Deporte, 15(3), 231-236.

22. Riera, J. R. (1995). Estrategia, táctica y técnica deportivas. Apunts: educación fisica y deportes, (39), 45-56.

23. Rincón, D., Arnal, J., Latorre, A. \& Sans, A. (1995). Técnicas de Investigación en Ciencias Sociales. Madrid: Dykinson.

24. Sampedro, J. \& Cañizares S. (1993). Cuantificación del esfuerzo y de las acciones de juego del base de baloncesto, Clinic, 22, 8-11.

25. Sampedro, J. (1999). Fundamentos de táctica deportiva. Madrid: Gymnos.

26. Schelling, X., \& Torres-Ronda, L. (2013). Conditioning for basketball: quality and quantity of training. Strength y Conditioning Journal, 35(6), 89-94.

27. Sporner, M.L., Grindle, G.G., Kelleher, A., Teodorski, E.E., Cooper, R. 
\& Cooper, R.A. (2009). Quantification of activity during wheelchair basketball and rugby at the National Veterans Wheelchair Games: a pilot study. Prosthetics and Orthotics International, 33(3), 210-217.
28. Zaragoza, J. (1996). Baloncesto: conclusiones para en entrenamiento a partir del análisis de la actividad competitiva. Revista de Entrenamiento Deportivo, tomo X, no 2, 21-27. 